\title{
0 comércio internacional do açúcar sob a perspectiva do modelo gravitacional
}

\section{The international sugar trade under the model of the gravitational perspective}

\author{
Roselis N. Mazzuchetti1,* e Pery F. A. Shikida² \\ ${ }^{1}$ Universidade Estadual do Paraná - Campus de Campo Mourão, Campo Mourão, Paraná, Brasil \\ 2 Universidade do Oeste do Paraná - Campus de Toledo, Toledo, Paraná, Brasil \\ (*E-mail: profbibi01@gmail.com) \\ http://dx.doi.org/10.19084/RCA16062
}

Recebido/received: 2016.05.11

Aceite/accepted: 2017.01.07

\begin{abstract}
R E S U M O
O objetivo deste trabalho foi estudar o comércio internacional do açúcar sob a perspectiva do modelo gravitacional. Foram coletados dados de 87 maiores exportadores de açúcar extraídos do banco de dados UNComtrade. As variáveis utilizadas foram o PIB, população, distância, preço, área do país exportador e dummies de participação do país exportador em um bloco econômico. Os dados em painel para o modelo gravitacional com Efeitos Aleatórios e correção de heterocedasticidade, demonstraram que as variáveis independentes explicam, no geral, 53,41\% das exportações mundiais de açúcar de 2000 a 2012. Somente os coeficientes da variável distância e as dummies incluídas para captar o efeito das exportações mundiais de açúcar para os países membros do CARICOM e CAFTA-DR apresentaram significância estatística. Ainda assim, o sinal da distância foi positivo, indicando que um aumento de $1 \%$ na distância eleva as exportações de açúcar em 1,42\%. De acordo com o modelo gravitacional, este resultado reflete uma ocorrência inesperada. Não obstante, a explicação desta relação está nas vantagens competitivas dos países exportadores de açúcar, especialmente o Brasil, cujo market share é elevado, além de que o produto sofre fortes restrições de comercialização, como subsídios, cotas e outras limitações à importação.
\end{abstract}

Palavras-chaves: Açúcar, Comércio Internacional, Modelo gravitacional, Agronegócios.

\section{A B S T R A C T}

The objective of this paper was to study the international sugar trade from the perspective of the gravity model. Data were collected from 87 major exporters of sugar extracted from UNComtrade database. The variables used were GDP, population, distance, price, the exporting country and area dummies of the exporting country participation in an economic bloc. The panel data for the gravity model with Random Effects and heteroscedasticity correction showed that the independent variables explain, in general, 53.41\% of world exports of sugar from 2000 to 2012. Only the variable distance coefficients and included dummies to capture the effect of global sugar exports to the CARICOM member countries and CAFTA-DR statistically significant. Still, the distance the signal was positive, indicating that an increase of $1 \%$ in the distance raises sugar exports in $1.42 \%$. According to the gravitational model, this result reflects an unexpected occurrence. However, the explanation of this relationship is the competitive advantage of countries exporting sugar, especially Brazil, whose market share is high, and that the product suffers strong marketing restrictions, such as subsidies, quotas and other restrictions on imports.

Keywords: Sugar, International Commerce, Gravitational Model, Agribusiness.

\section{INTRODUÇÃo}

A cadeia produtiva do açúcar ocupa um lugar de grande destaque no agronegócio mundial. O consumo no mundo cresceu vertiginosamente no último século, de oito milhões de toneladas em 1920, chegou a 163 milhões de toneladas em 2011 (USDA, 2013). A expansão foi diretamente impulsionada pelo aumento da renda per capita, especialmente nos países em desenvolvimento da Ásia, 
África e América Latina. Além do consumo pelas famílias, o açúcar é matéria-prima fundamental para o setor alimentício (refrigerantes, biscoitos, alimentos em geral e na indústria farmacêutica).

As exportações do açúcar de 2010 a 2013 foram em torno de 55.618.000 toneladas tendo como maiores exportadores, nesta ordem: Brasil, Tailândia, Austrália, Índia, Guatemala e União Europeia e, como maiores importadores encontram-se a União Europeia, Indonésia, Estados Unidos, China, Japão e Rússia. Em relação ao consumo, os maiores consumidores de açúcar do mundo são, respectivamente, Índia, UE, China, Brasil e EUA, que juntos respondem por aproximadamente $49,3 \%$ do consumo mundial do produto. (USDA, 2013)

Por ser um produto consumido mundialmente, podendo ser derivado de uma série de matérias-primas (cana, beterraba, milho, etc.) e de grande impacto nas economias (dada sua importância na segurança alimentar1), o açúcar é um dos mais protegidos comercialmente e por isso sofre muitas interferências, seja nos países produtores ou consumidores.

A partir dessa contextualização se faz mister entender os principais fatores que determinam o comércio internacional do açúcar no mundo. O modelo gravitacional, a fortiori, propõe originalmente que o comércio internacional é influenciado pelo PIB, população e distância. Neste estudo agregou-se as variáveis preço, área territorial do país exportador e como variáveis dummies buscou-se verificar como as transações comerciais são influenciadas fortes dentro dos blocos econômicos que possuem grandes produtores do açúcar.

O modelo gravitacional foi proposto pela primeira vez, independentemente, por Tinbergen (1962) e Pöyhönen (1963) e mais tarde foi aperfeiçoado por Linnemann (1966). Tinbergen utilizou uma analogia com a lei universal da gravitação de Newton para descrever os padrões de comércio bilateral agregado que flui entre dois países (Sá Porto, 2002).

\footnotetext{
${ }^{1} \mathrm{O}$ açúcar é um produto importante na segurança alimentar que além de ser fonte de energia alimentar, desempenha um papel importante na preservação dos alimentos e na extensão do tempo de prateleira. Ademais, a substituição ou remoção do produto açúcar nos alimentos altera suas características como o sabor, textura e aparência, o que pode resultar num produto diferente, afetando o gosto e expectativas do consumidor. (Cooper, 2012).
}

Utilizando modelagens diferentes, uma série de estudos forneceu bases teóricas para o modelo gravitacional voltado ao comércio, a citar Anderson (1979), Anderson e Van Wincoop (2003), Bergstrand (1985 e 1989), que discursam sobre os fundamentos microeconômicos da equação, enquanto que as discussões teóricas do modelo têm sido discutidas por pesquisadores como Krugman e Obstfeld (2010).

O modelo gravitacional tem sido amplamente empregado para explicar os fluxos de comércios bilaterais entre países, pouco se têm utilizado para explicar o comportamento de um único produto. Há um número limitado de trabalhos que enfocam um só produto, com destaque ao trabalho de Conforti e Rapsomaniskis (2005) que, ao apresentar o modelo, os autores substituem o produto açúcar pelas exportações de tabaco, em razão da falta ou limitação de dados para o período de 1988-2004 e pelo produto não possuir livre comércio na União Europeia, já que o tema tratava do impacto da reforma da política do açúcar na UE sobre os países subdesenvolvidos. Assim entende-se que, embora o modelo seja bastante utilizado, pouco foi aplicado per se ao produto açúcar.

\section{MATERIAIS E MÉTODOS}

Para a realização deste estudo e embora não esteja apresentado neste artigo, foi realizado um fichamento dos estudos realizados em livros, teses, artigos sobre as teorias do comércio internacional, as negociações da OMC, acordos e barreiras comerciais, tratando-se de uma revisão da literatura que é uma parte essencial para o processo da pesquisa e tem como propósito avaliar e arremeter o estado da arte em um campo do conhecimento (Volpato, 2013).

Para a coleta de dados dos valores das exportações mundial do produto açúcar foi utilizado as informações do banco de dados UN Comtrade. As demais variáveis foram extraídas dos bancos de dados: distância entre os países (CEPII), PIB (World Bank), população (WTO).

Os dados foram dispostos em painel, sendo estudados 87 países exportadores de açúcar, sendo: África do Sul, Alemanha, Arábia Saudita, Argentina, Austrália, Áustria, Barbados, Bélgica, Belize, 
Bielorússia, Bolívia, Bósnia e Herzegovina, Botswana, Brasil, Bulgária, Canadá, Chile, China, Colômbia, Costa Rica, Costa do Marfim, Croácia, Dinamarca, El Salvador, Equador, Eslováquia, Eslovénia, Espanha, Estados Unidos da América, Estónia, Federação Russa, Fiji, Filipinas, Finlândia, França, Grécia, Guatemala, Guiana, Honduras, Hong Kong, Índia, Indonésia, Irlanda, Itália, Jamaica, Japão, Líbano, Luxemburgo, Macedónia (ARJ), Madagáscar, Malawi, Malásia, México, Moçambique, Namíbia, Nova Caledónia, Nicarágua, Noruega, Países Baixos, Paquistão, Panamá, Paraguai, Perú, Polónia, Portugal, Quénia, Reino Unido, República Checa, República da Coreia, República de Maurício, República Dominicana, Roménia, Saint Kitts e Nevis, Samoa, Singapura, Sri Lanka, Sudão, Suécia, Suiça, Tailândia, Trinidad e Tobago, Ucrânia, Uganda, Tanzânia, Vietname, Zâmbia e Zimbabwe. O gráfico da Figura 1 justifica a escolha dos países utilizados nos dados em painel para a estimação da equação gravitacional deste estudo.

Pode-se observar que após o ano de 2008 os 87 países que fazem parte deste estudo abrangem quase $100 \%$ das transações de exportações da commodity açúcar, tornando-se uma amostra considerável. Cabe informar que o primeiro critério para escolha dos países foi de que o mesmo tivesse realizado transações de exportação em pelo menos 10 anos entre 2000 e 2012.

Para determinação da equação, utilizou-se como variável dependente "exportações" e as variáveis independentes o PIB, população, distância entre os países, preço, área do país exportador e dummies de participação do país exportador em bloco econômico (MERCOSUL, União Europeia, CARICOM, CAFTA-DR, APEC e BRIC), tendo a seguinte configuração:

$\ln \mathrm{X}_{\mathrm{ij}}=\beta_{0}+\beta_{1} \ln \mathrm{Y}_{\mathrm{i}}+\beta_{2} \ln \mathrm{Y}_{\mathrm{i}}+\beta_{3} \ln \mathrm{P}_{\mathrm{i}}+\beta_{4} \ln \mathrm{P}_{\mathrm{i}}+\beta_{5} \ln \operatorname{Dist}_{\mathrm{ij}}$ $+\beta_{6}$ Preço $+\beta_{7}$ Área $+\beta_{8}$ Mercosul $+\beta_{9} U E+\beta_{10}$ Caricom $+\beta_{11}$ Cafta-dr $+\beta_{12}$ APEC $+\beta_{13} B R I C+\mathrm{e}_{\mathrm{ij}}$

Em que:

$i=$ País e $j=$ Período (ano)

$X_{i j}$ é o valor corrente em dólares das exportações;

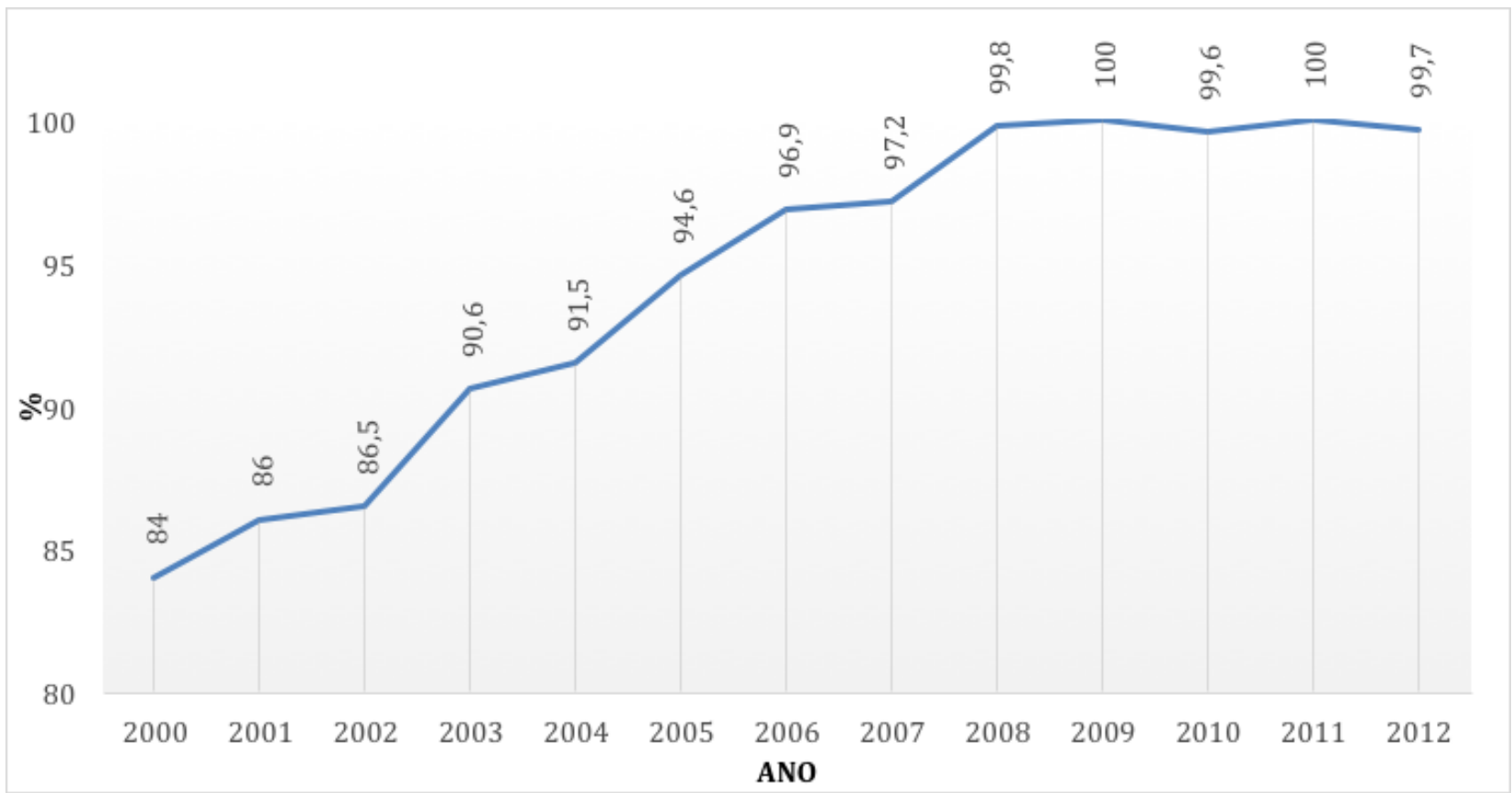

Figura 1 - Participação dos 87 países nas exportações mundiais de açúcar de 2000 a 2012. 
$Y_{i}$ é o PIB do país exportador ${ }_{\mathrm{i}}$ e $Y_{j}$ é o PIB médio mundial;

$P_{i}$ é a População do país exportador e $P_{j}$ é a População média mundial;

Dist ${ }_{i j}$ é a distância entre a capital do país exportador e média das distâncias dos países importadores;

Preço é o preço internacional da commodity açúcar;

Área é a extensão territorial do país exportador;

Mercosul, EU, Caricom, Cafta-DR, APEC e BRIC são variáveis dummy que possui valor 1 caso o país exportador pertença ao agrupamento econômico referido e 0 para os demais casos;

A transformação das variáveis por meio da função logarítmica foi realizada dada a necessidade de incorporação da não-linearidade ao método de regressão simples. Ao invés de uma relação linear constante, este modelo possibilitará uma relação percentual que dará mais conta da não linearidade do fenômeno (Wooldridge, 2010).

Ao construir o modelo gravitacional foi necessário averiguar a dimensão das relações existentes entre as variáveis independentes do modelo, que objetivam explicar as transações comerciais envolvendo o açúcar. Espera-se que entre as variáveis independentes não existam relações lineares exatas ou quase exatas, capazes de configurar um problema conhecido por multicolinearidade (Wooldridge, 2010).
Um modo de averiguar se as variáveis utilizadas apresentam este tipo de problema é analisar as relações entre os regressores do modelo. Para isso foi rodada a correlação entre as variáveis que comumente compõe o modelo gravitacional, cujos resultados são apresentados no Quadro 1.

Para a estimação do modelo utilizou-se as técnicas: modelo Pooled, Efeitos Fixos ou Efeitos Aleatórios. O modelo Pooled considera que o comportamento para todos os indivíduos e ao longo do tempo é uniforme e que todas as observações são homogêneas, não sendo considerados efeitos referentes a unidades de seção cruzada e período de tempo analisado. No modelo de Efeitos Fixos (EF), de modo geral, o intercepto varia para cada unidade analisada, porém são constantes ao longo do tempo, daí a denominação de Efeitos Fixos. Já, o modelo de Efeitos Aleatórios (EA) pressupõe que o intercepto de uma unidade específica é um elemento aleatório de um grupo ou população maior onde o intercepto representa um valor médio de todos os interceptos de corte transversal (Gujarati, 2006).

As ferramentas aceitas e utilizadas neste estudo para encontrar o modelo Pooled, Efeitos Fixos ou Efeitos Aleatórios são o teste de Chow, o teste de Hausman e o teste LM (Lagrange multiplier) de Breuch-Pagan.

O teste de Chow compara a Soma dos Quadrados dos Resíduos da regressão rodada pelo modelo Pooled com a regressão rodada para Efeitos Fixos, podendo ser aplicada a estatística F para decidir "to pool or not to pool" a estimação. Neste teste a hipótese nula é que o modelo Pooled é o mais adequado,

Quadro 1 - Quadro 1 - Correlação entre as variáveis do modelo utilizado

\begin{tabular}{|c|c|c|c|c|c|c|c|c|}
\hline & $\exp$ & pib_exp & pib_mun & pop_exp & pop_mun & area_exp & preco & Dist \\
\hline Exp & 1,0000 & & & & & & & \\
\hline pib_exp & $0,0959^{*}$ & 1,0000 & & & & & & \\
\hline pib_mundial & 0,0750 & $0,1237^{*}$ & 1,0000 & & & & & \\
\hline pop_exp & $0,1688^{*}$ & $0,7361^{*}$ & 0,0214 & 1,0000 & & & & \\
\hline pop_mundial & $0,0765^{* *}$ & $0,1214^{*}$ & $0,9794^{*}$ & 0,0218 & 1,0000 & & & \\
\hline area_exp & $0,1304^{*}$ & $0,4964^{*}$ & 0,0000 & $0,7685^{*}$ & 0,0000 & 1,0000 & & \\
\hline Preço & 0,0457 & $0,1015^{*}$ & $0,8297^{*}$ & 0,0187 & $0,8558^{*}$ & $-0,0000$ & 1,0000 & \\
\hline distância & $0,6701^{*}$ & $0,1603^{*}$ & 0,0131 & $0,2147^{*}$ & 0,0130 & $0,1462^{*}$ & $-0,0267$ & 1,000 \\
\hline
\end{tabular}

Fonte: Elaboração própria a partir dos dados coletados.

* Estatisticamente significante para $p<0.05 e$ ** para $p<0,10$. 
uma vez que não ocorreu uma mudança estrutural no relacionamento entre as variáveis do modelo, ou seja, existe homogeneidade na constante se a hipótese nula é rejeitada e admite-se a existência de heterogeneidade na constante, sendo o efeito fixo o modelo mais adequado.

O teste de Hausman escolhe a melhor estimativa entre os modelos de Efeitos Fixos e Efeitos Aleatórios e tem como premissa testar a correlação entre os efeitos individuais e os Efeitos Aleatórios e regressores. Assim, a hipótese nula é que ambos os modelos EF e EA não diferem substancialmente, pois não existe correlação, sendo ambos os estimadores consistentes, mas o primeiro é ineficiente. Se a hipótese nula for rejeitada, apenas um dos modelos é consistente, no caso o modelo de Efeitos Fixos, uma vez que existe correlação entre os efeitos individuais (Gujarati, 2006).

Para testar a presença de correlação entre as variáveis do modelo Pooled e Efeitos Aleatórios utilizou-se o teste LM de Breusch-Pagan. A hipótese nula no teste LM é que as variações entre as entidades é zero. Isto é, não há diferença significativa entre as unidades (ou seja, nenhum efeito do painel). Assim, ocorrendo a hipótese nula o modelo mais adequado é o Pooled. Rejeitando a hipótese nula, o modelo de Efeitos Aleatórios é preferível ao Pooled.

No contexto de dados em painel, deve-se atentar aos problemas de estimação e inferência. Em relação às propriedades de séries temporais os principais problemas são de regressão espúria, não-estacionariedade e a autocorrelação serial. Gujarati (2006) afirma que a estacionariedade ocorre quando a média, a variância e autocovariância não variam ao longo do tempo, possibilitando a realização de inferências sobre a população, facilitando as previsões.

Para verificar a estacionaridade ou a não-estacionaridade da série pode-se utilizar uma variedade de testes para raízes unitárias. Segundo Cazarotto (2006, p.11), os testes de raiz unitária aplicados em dados na forma de painel "tem sido desenvolvidos para melhorar o poder estatístico dos testes de estacionaridade convencional (baseados apenas em séries temporais) combinando informação de séries de tempo com informações cross-section".
Este estudo utiliza o teste de Im Pesaran Shim (IPS), proposto em 2003 e que considera um processo autoregressivo utilizando a representação do Teste de Dickey e Fuller Aumentado (ADF). Este teste adquire a estrutura do ADF ao permitir que as defasagens para a variável dependente possam ser inseridas o que possibilita a autocorrelação do erro para cada série (Gujarati, 2006). A expressão com $\beta$ variando por cada item é a seguinte:

\section{$\Delta y_{i, t}=\alpha_{i}+\beta_{i} y_{i, t-1}+\varepsilon_{i, t} \quad i=1, \ldots, N \quad t=1, \ldots, T$}

As seguintes hipóteses estão envolvidas no teste IPS: $H_{0}: \beta i=0 \quad \forall i$, ou seja, todo o painel é estacionário; $H_{1}: \exists i$ tal que $\beta i<0$, ou seja, algum painel pode ser estacionário

Outro problema ligado às series temporais é a autocorrelação. A autocorrelação existe quando os erros $u_{i t}$ do mesmo indivíduo não são independentes, assim, são correlacionados em relação ao tempo. Os problemas de autocorrelação são diagnosticados de diversas formas, baseando-se em vários pressupostos em relação à natureza dos efeitos individuais. Este estudo utiliza o teste de Wooldridge, que se trata de um teste muito flexível e se baseia em pressupostos mínimos. A hipótese nula é a de que não existe correlação e a outra hipótese constata-se que existe a correlação (Wooldridge, 2010).

A heterocedasticidade é um problema com os dados transversais, surge quando a variância dos erros de cada unidade não é constante. Os testes mais utilizados para verificar problemas de heterocedasticidade são o teste modificado de Wald e o teste do LM (Multiplicador de Lagrange) desenvolvido por Breusch e Pagan em 1980. Este estudo utilizou o Teste LM Breusch-Pagan, cuja hipótese nula $\left(H_{o}\right)$ é a de que não existe problemas de heterocedasticidade e a hipótese $\left(H_{1}\right)$ traduz um problema de heterocedasticidade (Cardoso, 2011; Campos, 2013).

\section{RESULTADOS E DISCUSSÃO}

Após a coleta e o exame do formato da distribuição dos dados, da verificação de ocorrência de valores atípicos e do grau de variação da amostra observada 
por meio da estatística descritiva foi rodada a correlação entre as variáveis do modelo (Quadro 1), procedimento necessário para a validação da aplicação do método gravitacional, apresentando o seguinte resultado: a) as variáveis PIB do país exportador (pib_exp), população (pop_exp), área territorial dos exportadores (área_exp), distâncias apresentaram relação estatisticamente significante (nível de $\mathrm{p}<0.05$ ) com a variável dependente valores exportados (exp) do modelo; b) a princípio todas as variáveis apresentam relação diretamente proporcional com a variável a ser explicada. Isto contradiz, em algum grau, as expectativas. c) observa-se também que as variáveis não apresentaram relações de linearidade quase perfeita, um bom sinalizador para ausência de multicolinearidade no modelo.

O teste Im, Pesaran e Shin que verificaram a estacionaridade ou não estacionaridade dos dados rejeitaram a hipótese nula em que todo o painel é estacionário. Ressalta-se que foi realizado o teste também para os resíduos obtendo-se o mesmo resultado. Este procedimento deu maior robustez à análise.

Os resultados obtidos na escolha da melhor equação gravitacional por meio dos modelos estimados, Pooled, de Efeitos Fixos e o Efeitos Aleatórios foram os seguintes:

O teste de Chow que compara o modelo Pooled e o de Efeitos Fixos, teve como resultado $\mathrm{F}(86,1038)$ $=25,6$ e $\mathrm{p}=0.00$ onde Prob $>\mathrm{F}=0,000$, rejeitando a hipótese nula e mostrando que o modelo de Efeitos Fixos é preferível ao Pooled.

O teste de Hausman que contribuiu na decisão entre os modelos de Efeitos Fixos e Aleatórios aceitou a hipótese nula de erros não sistemáticos para o modelo, onde o modelo de Efeitos Aleatórios é preferível ao de Efeitos Fixos.

O teste LM de Breusch-Pagan, que avalia os resíduos de modelo estimado por Mínimos Quadrados Ordinários, permite verificar a estimação mais adequada entre os modelos Pooled e Efeitos Aleatórios mostrou que a variância $(u)$ é diferente de zero, rejeitando-se a hipótese nula em favor do modelo de Efeitos Aleatórios.
Assim, os testes indicaram que o modelo de Efeitos Aleatórios é melhor em relação aos modelos Pooled e de Efeitos Fixos.

Os resultados do teste de Wooldridge para os dados coletados indicou a ausência de autocorrelação, ou seja, o teste falhou em rejeitar a hipótese nula de ausência de autocorrelação de primeira ordem. No entanto, o teste Breucsh-Pagan que detecta a presença de heterocedasticidade rejeitou a hipótese nula de variância constante, o que indica a presença de heterocedasticidade. Assim, o modelo de Efeitos Aleatórios foi estimado com correção de heterocedasticidade. O Quadro 2 apresenta as equações estimadas, bem como o resultado dos testes realizados para definir o melhor modelo e para detectar a heterocedasticidade e autocorrelação.

Os resultados mostram que, de acordo com o modelo de Efeitos Aleatórios com correção de heterocedasticidade, as variáveis independentes explicam, no geral, 53,41\% da variável dependente. Entre as unidades (R-sq between), o ajuste do modelo é de 50,08\% e dentro das unidades (R-sq within) o ajuste é de $58,26 \%$. Assim, o PIB dos países exportadores, o PIB mundial, a população dos países exportadores, a população mundial, a extensão territorial dos países exportadores, o preço do açúcar, a distância e as dummies MERCOSUL, União Europeia, CARICOM, CAFTA-DR, APEC e BRIC explicam $53,41 \%$ das exportações mundiais de açúcar no período de 2000 a 2012.

A literatura apresenta vários trabalhos que utilizam o modelo gravitacional com coeficientes de determinação $\left(\mathrm{R}^{2}\right)$ não elevados. Não obstante, tal fato pode eventualmente ocorrer quando são utilizadas variáveis com valores desagregados. Segundo Castilho (2002, p. 167-168).

\footnotetext{
“Globalmente observa-se que, ao contrário dos modelos agregados que apresentam coeficientes de determinação relativamente altos (excedendo, frequentemente, 0,8), os modelos com um maior nível de desagregação apresentam valores bem inferiores [...]. Isso se explica por um tipo de "viés de desagregação", ou seja, algumas variáveis, como PIB ou população, que mostram em grande medida os fluxos agregados, têm sua capacidade explicativa reduzida quando se desce ao nível desagregado. “
} 
Quadro 2 - Equação gravitacional estimada para as exportações mundiais de açúcar entre 2000 e 2012 - 87 países

\begin{tabular}{|c|c|c|c|c|}
\hline Variáveis & Regressão Pooled & Efeitos Fixos (EF) & Efeitos Aleatórios (EA) & $\begin{array}{c}\text { EA c/ correção } \\
\text { de heterocedasticidade }\end{array}$ \\
\hline \multirow{2}{*}{ Constante } & $-125,6816$ & $-147,9663$ & $-133,9686$ & $-133,9686$ \\
\hline & $(182,5642)$ & $(116,5275)$ & $(116,1949)$ & $(124,8233)$ \\
\hline \multirow{2}{*}{ PIB dos países exportadores } & $-0,1603$ & $-0,0635$ & $-0,0939$ & $-0,0939$ \\
\hline & $(0,0887)$ & $(0,3719)$ & $(0,2189)$ & $(0,2873)$ \\
\hline \multirow{2}{*}{ PIB mundial } & 0,1746 & 0,0334 & 0,0711 & 0,0711 \\
\hline & $(2,4829)$ & $(1,6499)$ & $(1,6023)$ & $(1,6162)$ \\
\hline \multirow{2}{*}{$\begin{array}{l}\text { População dos países } \\
\text { exportadores }\end{array}$} & $0,4567^{*}$ & $-3,5906^{*}$ & 0,3209 & 0,3209 \\
\hline & $(0,1141)$ & $(1,6652)$ & $(0,3181)$ & $(0,3234)$ \\
\hline \multirow{2}{*}{ População mundial } & 5,1674 & 9,2680 & 5,7123 & 5,7123 \\
\hline & $(11,2803)$ & $(7,3132)$ & $(7,1703)$ & $(7,5003)$ \\
\hline \multirow{2}{*}{$\begin{array}{l}\text { Extensão territorial dos países } \\
\text { exportadores }\end{array}$} & 0,1009 & - & 0,1495 & 0,1495 \\
\hline & $(0,0690)$ & - & $(0,2073)$ & $(0,1964)$ \\
\hline \multirow{2}{*}{ Preço do açúcar } & 0,2379 & 0,1803 & 0,1876 & 0,1876 \\
\hline & $(0,5035)$ & $(0,3200)$ & $(0,3203)$ & $(0,3147)$ \\
\hline \multirow{2}{*}{ Distância } & $1,4885^{*}$ & $1,4091^{*}$ & $1,4228^{*}$ & $1,4228^{*}$ \\
\hline & $(0,0491)$ & $(0,0379)$ & $(0,0374)$ & $(0,1359)$ \\
\hline \multirow{2}{*}{ Dummy MERCOSUL } & $2,0271^{*}$ & - & 2,0520 & 2,0520 \\
\hline & $(0,5686)$ & - & $(1,6910)$ & $(1,2225)$ \\
\hline \multirow{2}{*}{ Dummy União Europeia } & $0,9887^{*}$ & - & 0,8704 & 0,8704 \\
\hline & $(0,3223)$ & - & $(0,9025)$ & $(1,1309)$ \\
\hline \multirow{2}{*}{ Dummy CARICOM } & $3,0073^{*}$ & - & $2,9486^{*}$ & $2,9486^{*}$ \\
\hline & $(0,4862)$ & - & $(1,4586)$ & $(0,9631)$ \\
\hline \multirow{2}{*}{ Dummy CAFTA-DR } & $2,6045^{*}$ & - & $2,6572^{*}$ & $2,6572^{*}$ \\
\hline & $(0,3637)$ & - & $(1,0940)$ & $(0,6487)$ \\
\hline \multirow{2}{*}{ Dummy APEC } & $-2,0314^{*}$ & - & $-1,9829^{*}$ & $-1,9829$ \\
\hline & $(0,3294)$ & - & $(0,9502)$ & $(1,1625)$ \\
\hline \multirow{2}{*}{ Dummy BRIC } & $-0,1724$ & - & $-0,0311$ & $-0,0311$ \\
\hline & $(0,5241)$ & - & $(1,5825)$ & $(1,5589)$ \\
\hline Observações & 1.131 & 1.131 & 1.131 & 1.131 \\
\hline Grupos & - & 87 & 87 & 87 \\
\hline Períodos & - & 13 & 13 & 13 \\
\hline R-Squared & 0,5348 & - & - & - \\
\hline Adj R-squared & 0,5294 & - & - & - \\
\hline R-sq within & - & 0,5848 & 0,5826 & 0,5826 \\
\hline R-sq between & - & 0,0038 & 0,5008 & 0,5008 \\
\hline R-sq overall & - & 0,0152 & 0,5341 & 0,5341 \\
\hline Teste F & 98,79 & 243,63 & - & - \\
\hline Teste de Hausman & - & 6,55 & - & - \\
\hline Teste LM de Breusch-Pagan & $2.373,76$ & - & - & - \\
\hline Teste de Wald & - & - & $1.527,80$ & 384,62 \\
\hline Teste de Chow & 25,60 & - & - & - \\
\hline Teste de heterocedasticidade & - & - & 193,85 & - \\
\hline Teste de autocorrelação & - & - & 1,66 & - \\
\hline
\end{tabular}

Fonte: Resultado da pesquisa.

* Significativo para 5\% de significância.

Nota: os valores entre parênteses correspondem aos erros-padrão. Todas as variáveis estão expressas em logaritmo natural.

A variável dependente corresponde às exportações mundiais de açúcar. 
Feita esta explicação, vale dizer que o coeficiente de determinação entre $50 \%$ e $60 \%$ é aceitável tanto diante do modelo que foi proposto por este trabalho, bem como pelo que consta em literaturas que utilizaram o modelo gravitacional (Cardoso, 2011; Campos, 2013).

$\mathrm{Na}$ equação gravitacional estimada os resultados mostraram que somente os coeficientes da variável distância e as dummies incluídas para captar o efeito das exportações mundiais de açúcar para os países membros do CARICOM e CAFTA-DR apresentaram significância estatística. As demais foram não estatisticamente significativas, portanto, não cabendo explicações sobre suas elasticidades.

A variável distância apresentou sinal diferente do esperado. Segundo seu coeficiente, um aumento de $1 \%$ na distância eleva as exportações de açúcar em 1,42\%. Isto, a princípio, pode parecer um contrassenso. Entretanto, no caso do produto açúcar, a distância (ou custos de transporte, muitos do tipo FOB - Free on Board) é uma variável que pode ser superada pelas vantagens competitivas dos países produtores. O Brasil, conforme Shikida etal. (2011), maior produtor e exportador do produto $(45,3 \%$ do total exportado mundial), é detentor de vantagens comparativas no que concerne à disponibilidade de terras para a cana-de-açúcar que, aliados aos fatores favoráveis como clima, solo e variedades de cana perfeitamente adaptáveis à realidade nacional, reproduz uma elevada produtividade e, por consequência, um custo de produção muito baixo vis-à-vis seus congêneres internacionais. Outro aspecto importante é o fato de o País poder processar duas safras de cana-de-açúcar por ano, haja vista sua dimensão continental e privilegiada localização geográfica no hemisfério sul, sendo o pico de movimentação de cargas para mercados internacionais exatamente na entressafra dos principais fornecedores de açúcar no mercado mundial.

De acordo com Carvalho e Oliveira (2006), o custo de produção da tonelada de açúcar no Brasil é estimado em US\$ 140, enquanto na Austrália e Tailândia em US\$ 335 e na Europa de US\$ 710. Conforme a Associação de Produtores de Bioenergia do Estado do Paraná - Alcopar (2014) e a Unica (2014), se considerar somente o custo de produção do Estado de São Paulo, maior produtor e exportador dessa commodity (deteve $66,5 \%$ do total exportado pelo Brasil na safra 2013-2014), certamente o custo de produção da tonelada de açúcar cairá ainda mais. Em razão dessa vantagem, mesmo sendo o protecionismo ao açúcar presente nas relações comerciais de muitos países, o Brasil ainda exporta para 123 países localizados em todos os continentes, não se importando muito para a questão "distância". Anhesini et al. (2013, p. 875) complementa este contexto dizendo que:

“[...] a competitividade do açúcar brasileiro no exterior é fruto de uma série de mudanças de caráter exógeno e endógeno ocorridas no setor, que culminaram num maior dinamismo da atividade, mesmo num cenário de concentração industrial. A estabilidade do padrão de especialização das exportações de açúcar sinaliza uma maturidade do SAG em relação ao comércio internacional do produto. “

Outro fator que explica, em parte, o caráter do aumento da distância elevar as exportações de açúcar, ao invés de diminuir, está no fato de esta commodity ser para a maioria dos países um produto pertencente à cesta básica e uma fonte de energia alimentar muito utilizada. Ademais, o consumo do açúcar vem aumentando nos últimos anos, seja em função da entrada no mercado de pessoas com maior poder aquisitivo e/ou mudanças nos hábitos alimentares da população, principalmente dos países mais populosos do mundo (notadamente China e Índia). Neste sentido, de acordo com dados da FAO (2014a), a tendência é de crescimento no consumo de açúcar para os próximos anos. Os grandes consumidores como o Brasil e Estados Unidos consomem anualmente $65 \mathrm{~kg}$ e $33 \mathrm{~kg}$ per capita, respectivamente, enquanto que a Índia e China consomem $20 \mathrm{~kg}$ e $15 \mathrm{~kg}$ per capita ano, respectivamente. Caso a China adote, com o passar dos anos, um padrão de consumo semelhante aos grandes consumidores (não se despreza aqui as diferenças culturais significativas existentes entre estes países), os chineses deverão muito em breve duplicar suas importações. Assim, tendo esta necessidade premente de consumo, a distância entre os mercados não é uma variável que caso diminua, contribuirá necessariamente para aumentar as exportações açucareiras, ainda mais para os players que são competitivos e buscam aumentar seu market share. 
As dummies incluídas para captar o efeito das exportações mundiais de açúcar para os países membros do MERCOSUL, União Europeia, CARICOM, CAFTA-DR, APEC e BRIC foram estatisticamente insignificantes, exceto as dummies para os países membros do CAFTA-DR (Central American Free Trade Agreement and Dominican Republic) e CARICOM (Caribbean Community). Os coeficientes das dummies CARICOM e CAFTA-DR indicaram que, entre 2000 e 2012, as exportações de açúcar para os países membros destes blocos aumentaram, respectivamente, $1.807,92 \%$ e 1.325,63\%². Esta significância estatística foi para blocos econômicos cuja região, Caribe (onde também se localiza a República Dominicana), apresenta forte tradição na cultura canavieira e comércio açucareiro (Szmrecsányi, 1979; Shikida, 1997). Cumpre ressaltar que, conforme relatado nas variáveis descritivas do modelo, os blocos não tem grande peso sobre o número total das transações do período $(88,52 \%$ do valor total das transações de açúcar ocorreu fora do contexto dos blocos econômicos), e os pesos desses dois blocos econômicos no mercado do açúcar (CARICOM e CAFTA-DR) são baixos. Outrossim, existe um acordo bilateral entre EUA e México que permite que o México exporte açúcar para os EUA. Os norte-americanos também fizeram um acordo para importação desse produto da América Central e República Dominicana (Costa, 2004; FAO, 2014b).

Neste pormenor, assim como no caso anterior da variável distância, pode-se dizer que o mercado do açúcar - diante da maioria das variáveis dummies não estatisticamente significativas para os grandes blocos econômicos - e com suas especificidades ditadas amiúde por medidas protecionistas para um produto tipicamente estratégico do ponto de vista da segurança alimentar, mostra que este mercado é assaz idiossincrático e o caráter muito presente de intervenção contribui indubitavelmente para distorcer suas relações comerciais, contribuindo para explicar alguns dos resultados aqui expostos.

\footnotetext{
2 "[...] em modelos do tipo $\ln Y_{i}=\beta_{1}+\beta_{2} D_{i}$, a variação relativa de $Y$ (isto é, sua semi-elasticidade) em relação ao regressor binário que assume valores 1 ou 0 pode ser obtida por (antilogaritmo do $\beta_{2}$ estimado) -1 vezes 100 , isto é, por $\left(e^{\beta 2}-1\right) \times 100^{\prime \prime}$ (Gujarati, 2006, p. 270).
}

Não é preciso perscrutar a literatura correlata para que apontamentos sobre isto sejam evidentes. Para o Banco Nacional de Desenvolvimento Econômico e Social - BNDES; Centro de Gestão e Estudos Estratégicos - CGEE (2008, p. 55-56), por exemplo, uma "[...] complicação inescapável tem a ver com a relativa rigidez dos mercados internacionais de açúcar, com um volume apreciável de produto comercializado mediante cotas a preços que pouco refletem as pressões de oferta e demanda". Dias (2008) estudando o açúcar e álcool paranaenses por meio de testes de raiz unitária de Dickey-Fuller Aumentado e de co-integração de Johansen (mesmo São Paulo sendo hegemônico no setor, o Paraná é um importante player no mercado do açúcar), encontrou que um aumento de $1 \%$ na variável preço médio do açúcar internacional (com dois anos de defasagem) gera um aumento na oferta do açúcar de $0,37 \%$. Ou seja, mesmo com este estado destinando parcela expressiva de sua produção para o mercado externo, as sinalizações de preços internacionais não são plenamente repassadas para os produtores em virtude de fortes subsídios e medidas protecionistas existentes no caso do açúcar, que tem potencial de distorcer as relações comerciais nesse mercado internacional e dificultar o seu acesso.

Outro apontamento que deve ser relatado está no fato de dois dos principais produtores mundiais de açúcar (Brasil, 1ํㅡ, e Estados Unidos, 6oㅡ maior produtor) terem nas suas matérias-primas produtoras de açúcar destino também para o bioetanol biocombustível. "Naturalmente, a essa avaliação da viabilidade da produção de bioetanol, superpõem-se outras considerações, como compromissos e estratégias de mercado" (CGEE, 2008, p. 55). Destarte, não somente a segurança alimentar é opção estratégica para estes dois países mas também a segurança energética, e esta dubiedade pode provocar efeitos diretos no mercado açucareiro. Esta opção também é relatada por IPEA (2010, p.10):

“A questão dos preços constitui-se em um grande desafio para a produção de etanol no Brasil. Atualmente, os preços do etanol flutuam livremente, dependendo das variações da oferta e demanda. Uma das grandes vantagens do etanol vis-à-vis a gasolina é o preço do produto mais competitivo na relação etanol/gasolina a partir de $70 \%$. 
Quando isto não acontece ou não se vislumbra, os produtores de cana acabam escolhendo produzir e exportar o açúcar, por conhecerem o comportamento da preferência do consumidor pela gasolina."

Em suma, a aplicação do modelo gravitacional pela presente pesquisa corroborou de certa forma a natureza estratégica da commodity açúcar, cuja comercialização internacional, amiúde ditada por algum grau de protecionismo, e em alguns casos (notadamente Brasil e EUA) sendo produto complementar e/ou substituto ao etanol, permite a evidência de menos realismo no mercado açucareiro.

Fica, dessa maneira, convidado o leitor deste trabalho a fazer a sua breve síntese do confronto destes resultados com as teorias do comércio internacional, onde algumas asseveram que os ganhos no comércio se dão(rão) pela competitividade derivada de vantagens locacionais e/ou em termos de capacidades tecnológicas. Contudo, as relações de troca entre os países nem sempre se pautam em tais fundamentos, sendo as condições de negociação compartilhada entre dois países dependente, muitas vezes, de acordos com produtores locais e outras variáveis políticas.

\section{CONSIDERAÇÕES FINAIS}

Os resultados da equação gravitacional apresentaram os coeficientes da variável distância e as dummies CARICOM e CAFTA-DR com significância estatística. Contudo, a variável distância apresentou sinal diferente do esperado, apontando que um aumento de $1 \%$ na distância eleva as exportações de açúcar em 1,42\%. Esperava-se uma relação de variância inversamente proporcional ou ao menos mais fraca entre essas variáveis. Como explicação para este resultado cumpre frisar que para um importante player exportador mundial - o Brasil, a distância é uma variável que pode ser superada pelas suas vantagens competitivas. Ademais, o açúcar é um produto de extrema importância para a segurança alimentar e, num mercado internacional ditado amiúde por medidas protecionistas, a distância entre os mercados não é uma variável que caso diminua, contribuirá necessariamente para aumentar as exportações açucareiras. A relação entre custo e distância não é linear, por exemplo, e sua curva tem um comportamento distinto dado sua forma de transporte adotada para efetivar a transação da mercadoria. A busca por market share é mais relevante nesses casos.

Quanto às dummies para os países membros do CAFTA-DR e CARICOM, sua significância estatística corroborou a forte tradição no comércio açucareiro dos países que interagem nesses blocos. A não significância estatística para os grandes blocos, e a ocorrência de parcela das transações fora dos blocos, confirmou para o mercado internacional de açúcar sua relativa rigidez e idiossincrasia.

Observa-se, portanto, o quanto é idiossincrático e complexo o mercado internacional do açúcar, pois envolve o comportamento das variáveis estudadas e muitas outras variáveis não apontadas neste trabalho, além da atuação de diversos fatores agentes que possuem interesses distintos. Dessa forma, atingiu-se o objetivo proposto inicialmente, mas este trabalho não se esgota, já que o contexto está em permanente mudança, sendo necessários estudos contínuos para acompanhamento de sua evolução.

Algumas indicações para ampliar este estudo seria a de aplicar o modelo gravitacional exclusivamente para as exportações do açúcar brasileiro, pois além de ser o maior produtor e exportador é detentor de tecnologia e condições favoráveis para maior produtividade com menor custo e, ainda assim, enfrenta fortes barreiras para colocação de seu produto em diversos países. Outra indicação é a adoção ou acréscimo de novas variáveis possíveis de entender melhor os fluxos comerciais do produto açúcar como acordos, tarifas e outras barreiras comerciais ou técnicas. 


\section{REFERÊNCIAS BIBLIOGRÁFICAS}

ALCOPAR (2014) - Estatísticas-Mercados. Associação de Produtores de Bioenergia do Estado do Paraná. [cit. 2014.09.12]. http://www.alcopar.org.br/estatisticas/exp acu est2010.htm

Anderson, J.E. (1979) - A theoretical foundation for the gravity equation. American Economic Review, vol. 69, n. 1, p. 106-116.

Anderson, J.E. \& Wincoop, E.V. (2003) - Gravity with gravitas: a solution to the border puzzle. American Economic Review, vol. 93, n. 1, p. 170-192. http://dx.doi.org/10.1257/000282803321455214

Anhesini, J.A.R.; Camara, M.R.G.; Sereia, V.J. \& Shikida, P.F.A. (2013) - Sistema agroindustrial canavieiro no Brasil no período 1990/2010: análise de indicadores de competitividade internacional. Revista Econômica do Nordeste, vol. 44, n. 4, p. 867-878.

Bergstrand, J.H. (1985) - The gravity equation in international trade: some microeconomic foundations and empirical evidence. The Review of Economics and Statistics, vol. 67, p. 474-481.

Bergstrand, J.H. (1989) - The generalized gravity equation, monopolistic competition, and the factor-proportions theory in international trade. The Review of Economics and Statistics, vol. 71, p. 143-153.

CGEE (Orgs.) (2008) - Bioetanol de cana-de-açúcar: energia para o desenvolvimento sustentável. Banco Nacional de Desenvolvimento Econômico e Social (BNDES); Centro de Gestão e Estudos Estratégicos. BNDES, Rio de Janeiro, $316 \mathrm{p}$.

Campos, L.F. de (2013) - Análise das barreiras comerciais sobre a inserção da agricultura paranaense no mercado externo: reflexos da crise internacional de 2008. Dissertação de Mestrado. UNIOESTE, Toledo, 206 p.

Cardoso, R.D. (2011) - Uma análise do fluxo de comércio intrarregional no Mercosul utilizando um modelo gravitacional. Dissertação (Mestrado em Desenvolvimento Regional e Agronegócio), UNIOESTE, Toledo (PR), 68 p.

Carvalho, G.R. \& Oliveira, C. de (2006) - O setor sucroalcooleiro em perspectiva. Campinas: Embrapa Monitoramento por Satélite. 18 p. (Circular Técnica, 10). [cit. 2014-03-19] http://www.cnpm.embrapa.br/publica/ download/cit10 sugaralcool.pdf

Castilho, M.R. (2002) - O acesso das exportações do MERCOSUL ao mercado europeu. Pesquisa e Planejamento Econômico, vol. 32, n. 1, p. 149-198.

Cazarotto, S. (2006) - Teste de raiz unitária em modelo painel: uma aplicação a teoria da paridade real de juros na América Latina. Dissertação (Mestrado em Economia e Finanças). UFSC, Florianópolis (SC), 71 p.

Conforti, P. \& Rapsomaniskis, G. (2005) - The impact of the European Union sugar policy reform on developing and least developed countries. In: FAO Commodity Market Review. Rome, p. 89-124. ftp://ftp.fao.org/ docrep/fao/008/a0334e/a0334e01.pdf

Cooper, J.M. (2012) - Product Reformulation - can sugar be replaced in foods? International Sugar Journal, vol. 114, n. 1365, p. 642-645.

Costa, C.C. (2004) - Medidas protecionistas utilizadas pelos Estados Unidos e União Europeia para o açúcar: impacto sobre a economia das regiões exportadoras do Brasil. Tese de doutoramento, ESALQ/USP, Piracicaba/SP, $317 \mathrm{p}$.

Dias, L.C. (2008) - Determinantes das ofertas de açúcar e álcool paranaenses (1981-2006): uma análise de co-integração. Dissertação (Mestrado em Desenvolvimento Regional e Agronegócio), UNIOESTE, Toledo, 94 p.

FAO (2014a) - Sugar. Food and Agriculture Organization. http://www.fao.org/docrep/011/ai474e/ai474e08.htm1/4.

FAO (2014b) - Multilateral trade negotiations on agriculture: a resource manual. Food and Agriculture Organization. http://www.fao.org/docrep/003/x7352e/x7352e02.htm

Gujarati, D. (2006) - Econometria básica. 3 ed. Elsevier, Rio de Janeiro, 812 p.

IPEA (2010) - Biocombustíveis no Brasil: etanol e biodiesel. Comunicados do IPEA n. 53, Série Eixos do Desenvolvimento Brasileiro. Instituto de Pesquisa Econômica Aplicada (IPEA), Rio de Janeiro, 57 p.

Krugman, P. \& Obstfeld, M. (2010) - Economia Internacional: teoria e política. 5. ed. Makron Books, São Paulo.

Linnemann, H. (1966) - An econometric study of international trade flows. North Holland, Amsterdam.

Pöyhönen, P. (1963) - A tentative model for the volume of trade between countries. Welwirtschaftliches Archiv, vol. 90, n. 1, p. 93-99.

Sá Porto, P.C. de (2002) - Os impactos dos fluxos de comércio do Mercosul sobre as regiões brasileiras. Tese de Doutoramento. IE/UNICAMP, Campinas, $88 \mathrm{p}$. 
Shikida, P.F.A. (1997) - A evolução diferenciada da agroindústria canavieira no Brasil de 1975 a 1995. Tese de Doutoramento. ESALQ/USP, Piracicaba, $191 \mathrm{p}$.

Shikida, P.F.A.; Azevedo, P.F. de \& Vian, C.E. de F. (2011) - Desafios da agroindústria canavieira no Brasil pós-desregulamentação: uma análise das capacidades tecnológicas. Revista de Economia e Sociologia Rural, vol. 49, n. 3, p. 599-628. http://dx.doi.org/10.1590/50103-20032011000300004

Szmrecsányi, T. (1979) - O planejamento da agroindústria canavieira do Brasil (1930-1975). HUCITEC/UNICAMP, São Paulo, 540 p.

Tinbergen, J. (1962) - Shaping the world economy: suggestions for an international economic policy. Twentieth Century Fund, New York.

UNICA (2014) - Unicadata. União da Indústria de Cana-de-Açúcar (ÚNICA). http://www.unicadata.com.br/listagem. php?idMn $=43$

USDA (2013) - US agricultural trade update, monthly spreadsheet files. Economic Research Service, United States Department of Agriculture. http://usda.mannlib.cornell.edu/usda/usda.html

Volpato, G.L. (2013) - Ciência: da filosofia à publicação. 6 ed. Cultura Acadêmica, São Paulo, 377 p.

Wooldridge, J. (2010) - Introdução à econometria: uma abordagem moderna. 4 ed. Cengage Learning, São Paulo, $725 \mathrm{p}$. 